\title{
Determinants of food price inflation in Finland
}

\author{
Xavier Irz, Jyrki Niemi and Liu Xing \\ MTT Taloustutkimus, Latokartanonkaari 9,00790 Helsinki,xavier.irz@mtt.fi,jyrki.niemi@mtt.fi, \\ liu.xing@mtt.fi
}

\begin{abstract}
:
The agricultural commodity crisis of 2006-8 and the recent evolution of commodity markets have reignited anxieties in Finland over fast-rising food prices and food security. Although the impact of farm commodity price shocks on the final consumer is mitigated by a large degree of processing as well as the complex structure of the food chain, little is known about the strength of the linkages between food markets and input markets. Using monthly series of price indices from 1995 to 2010, we estimate a vector error-correction (VEC) model in a co-integration framework in order to investigate the short-term and long-term dynamics of food price formation. The results indicate that a statistically significant long-run equilibrium relationship exists between the prices of food and those of the main variable inputs consumed by the food chain, namely agricultural commodities, labour, and energy. When judged by the magnitude of long-run pass-through rates, farm prices represent the main determinant of food prices, followed by wages in food retail and the price of energy. However, highly volatile energy prices are also important in explaining food price variability. The parsimonious VEC model suggests that the dynamics of food price formation is dominated by a relatively quick process of adjustment to the long-run equilibrium, the half life of the transitional dynamics being six to eight months following a shock.
\end{abstract}

Key words: food prices, inflation, co-integration, price formation 


\section{Introduction}

In recent years, food prices in Finland have received much attention from the media, policy makers and the general public. Perhaps the main concern relates to the potential consequences for Finnish consumers and Finnish living standards of the upward trend in and increasing variability of agricultural commodity prices, following the international food crisis of 2006-8. For instance, in the summer of 2010, speculations about the effect that a Russian grain export ban caused by forest fires might have on the price of Finnish bread made the news, which resulted in the Minister of Agriculture and Forestry issuing statements in order to reassure the public and market participants that the inflationary effect of the ban would, in fact, be limited. At a more fundamental level, however, legitimate concerns exist in relation to the growing scarcity and variability of supply of agricultural commodities in the medium to long term due to a conjunction of factors. Climate change is now expected to lower average yields and increase yield variability in many production areas of the world. The growing scarcity of fossil fuels and restrictions on greenhouse gas emissions will also raise the energy cost of agricultural production, while bio-energy production increasingly competes with food production for the use of scarce natural resources. Meanwhile, economic and population growth world-wide put constant pressure on the demand side of the global food balance equation. There is therefore little doubt that, in the medium to long term, prices of agricultural commodities traded on international markets are going to increase at a rate exceeding that of inflation.

Anticipating the impact that this evolution might have on retail food prices and the economic well-being of the Finnish population is difficult, however, because agricultural commodities receive a large amount of processing before reaching retail stores. Yet the extent to which food markets are linked to other markets, including commodity markets, remains largely unknown in Finland as in most other countries. This paper tackles that issue by investigating the dynamics of food price formation in relation to the prices of the inputs used intensively in the food chain, namely agricultural commodities, energy and labour. Put simply, we seek to establish to what extent and how quickly changes in input prices influence food prices.

Against this background, we develop a cointegration analysis of Finnish food prices to make an empirical contribution to the existing literature on the determinants of food price inflation in high-income countries.

\section{Conceptual Framework and Data}

Although we do not attempt to build a fully structural model of food prices, economic theory guides the selection of explanatory variables. At a fundamental level, food prices reflect equilibrium between supply and demand forces, and the model should therefore include the main shifters of supply and demand. On the supply side, a cursory analysis of the cost structure of the food industry indicates that, in addition to raw agricultural commodities, two other inputs are likely to have a major impact on retail food prices: labour, which is used in processing, wholesale and retail; and energy, which is required for both the transformation of the raw commodities, and the transportation of food to the final consumer. The state of the technology also influences the position of the industry supply curve, but the process of technological change is implicitly proxied by a time trend in the model. On the other side of the equilibrium relationship, demand is influenced by the average and distribution of disposable income as well as changes in the demographic composition of the population, but the latter are unlikely to be very large in a homogenous country such as Finland with little population growth and limited immigration. Ultimately, the empirical model attempts to explain retail food prices by the unit costs of agricultural raw materials, energy, and labour, while income is ignored due to the unavailability of monthly data (see below). Technological and preference changes are captured by trends in the model.

Monthly price indices from Statistics Finland are used to build a data set from the time Finland joined the EU (January 1995) to February 2010 (the latest month available when the study started), giving a total of 182 observations. The decision to ignore data preceding Finland's entry into the EU is made for two reasons: first, EU entry was a major structural break for Finnish food markets, with the years preceding entry characterized by sharp price adjustments; and, second, Finland had to operate many changes in its collection and calculation of statistics so as to harmonise its system with that of the EU, which makes it difficult to merge pre- and post-entry data.

Food prices are measured by the component of the Consumer Price Index (CPI) corresponding to food and non-alcoholic beverages. Farm prices are measured by the price index of agricultural goods output, including fruits and vegetables but excluding fur skins. Labour unit cost in food retail is measured by 
seasonally-adjusted wage index for retail sales in non-specialised stores, with food, beverages and tobacco dominating. Finally, energy prices are drawn from the database on prices of the means of agricultural production for the input category labelled 'Energy and lubricants'. Unfortunately, there are no monthly statistics on disposable income available in Finland and the variable is therefore ignored in subsequent analysis ${ }^{1}$.

The data rescaled to a 1995 base year is presented in Figure 1, from which a few remarks are in order. Overall food prices in Finland have increased since 1995 at the economy-wide rate of inflation, but the period since mid-2007 has seen a particularly fast rise in food prices, followed by a significant decline. The recent food crisis has therefore had a visible impact on retail Finnish food markets. However, food prices are also much more stable than those of commodities, with energy prices in particular showing large volatility. By contrast, wages in food retail have grown almost linearly at a rate close to that of per capita income, with the exception of a brief break in trend around 2008. Finally, we note the clear seasonality of agricultural prices, which is addressed in the econometric model by including monthly dummies.

\section{Figure 1: Price indices of food and related variables $(1995=100)$}

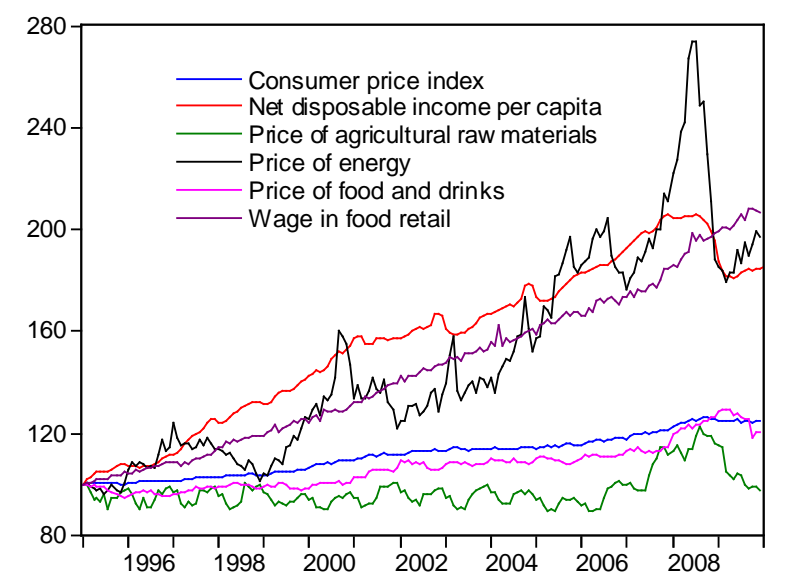

\section{Overview of time-series analysis}

The first step of the analysis focuses on the stochastic properties of the series by testing for the presence of unit roots. This allows for the identification of stationary and non-stationary time series, which in turn permits the specification of a model that should not produce spurious results. Provided that the variables are non-stationary as is usually the case with time-series of prices, the existence of a long-run equilibrium among variables is then tested by applying the Johansen approach, which starts with the specification of a vector autoregression (VAR) model of order $\mathrm{k}$ :

$$
z_{t}=\mu+A_{1} z_{t-1}+.+A_{k} z_{t-k}+\varepsilon_{t}
$$

In equation $(1), z_{t}$ denotes the $(4 \times 1)$ vector of indices of food prices, farm prices, energy prices, and wages in food retail, while $\varepsilon_{t}$ denotes the white-noise error term. A key feature of the VAR model is that it does not impose any a priori restriction on the exogeneity of variables, which is attractive in the present context because of the possibility of bi-directional causality. For instance, given that labour is an important input in food processing and retail, the wage rate is likely to influence food prices. However, high food prices could also give food manufacturers and retailers more room when negotiating wages with employees.

The idea behind the approach proposed by Johansen (1995) is to reformulate the VAR model so as to impose and test the validity of cointegrating constraints in the following equation:

$$
\Delta z_{t}=\mu+\Gamma_{1} \Delta z_{t-1}+.+\Gamma_{k-1} z_{t-k+1}+\Pi z_{t-k}+\varepsilon_{t}
$$

The $(4 \times 4)$ matrices $\Gamma_{i}(\mathrm{i}=1, \ldots \mathrm{k}-1)$ guide the short-run dynamics of the model, while any long-run relationships are captured by the $(4 \mathrm{x} 4)$ matrix $\Pi$. The full dynamics of the system is better understood by re-writing model (2) in vector error-correction (VEC) form, which involves, when possible, decomposing matrix $\Pi$ into the product $\alpha \beta$ '. Each vector of the ( $4 \times r)$ matrix $\beta$ describes a stationary co-integration linear

\footnotetext{
${ }^{1}$ The figure below plots the income series extrapolated from annual data.
} 
relationship that holds among the variables in the long-run equilibrium, while the $(4 \mathrm{x} r)$ matrix $\alpha$ gathers the coefficients that dictate the speed of adjustment of $z_{t}$ to the long-run equilibrium. The method proposed by Johansen (1995) to establish whether this decomposition is possible relies on a test of the rank $r \leq 4$ of matrix $\Pi$. If $r=0$, no cointegration relationship exists, while if $r=4$ all the variables in $z_{t}$ are stationary. More usually, matrix $\Pi$ has reduced rank $r$ corresponding to the number of cointegration relationships.

\section{Empirical results}

\section{Unit Root and co-integration tests}

Recognizing the lack of robustness of any given test, the presence of unit roots was analyzed with the Augmented Dickey-Fuller (ADF), Phillips-Perron (PP) and Kwiatkowski, Phillips, Schmidt, and Shin (KPSS) tests. Food prices were clearly found to be integrated of order one (I(1)), but the results were not consistent across tests for the other three series. However, the weight of the evidence, and the severity of the statistical consequences of treating a non-stationary variable as stationary, led us to consider that energy prices, wages, and farm prices were also I(1). The Johansen procedure was then applied to test for the existence of co-integration relationships among the four variables. The lag length in the unrestricted VAR was set to two months by maximising the value of several information criteria, and co-integration was then tested for models differing in terms of the inclusion of exogenous variables (constant an trend) in the longrun and short-run models (Harris \& Sollis, 2003, p. 133). By application of the Pandula principle, we concluded to the presence of one co-integrating relationship and that the best specification of the model featured constants in both short-run and long-run models.

\section{The long-run cointegration relationship}

The normalised long-run cointegration relationship among the four variables estimated by the Johansen technique is as follows:

$$
\ln P_{\text {food }}=\underset{(5.64)}{0.312 *} \ln P_{a g}+\underset{(1.75)}{0.055 \ln *} P_{e n}+\underset{(7.04)}{0.258 * \ln } P_{w}+1.692
$$

In equation (3), $P_{f o o d}, P_{a g}, P_{e n}$ and $P_{w}$ denote respectively the price indices of food, agricultural commodities and energy as well as the wage rate in food retail, while $t$-ratios of the estimated coefficients are reported in parentheses. Ignoring the constant which has no economic meaning and simply reflects units of measurement, the estimated coefficients have the expected positive sign, indicating a positive long-run relationship between food prices and the three major production factors used in the food chain. Further, the long-run relationships between food and input prices are statistically significant, very strongly so in the case of agricultural commodities and wages, but only at the $8 \%$ level in the case of energy. Given the log-log nature of the estimated equation, the coefficients can be interpreted as pseudo-elasticities reflecting the relative influence of each variable on food prices. On that basis, the estimation results indicate that agricultural prices represent the main determinant of food prices, with any $10 \%$ increase in price at the farm gate eventually resulting in a more than $3 \%$ increase in food prices at retail level. Next comes the wage rate in food retail, with a pseudo-elasticity, or pass-through rate, of just over a quarter, and finally energy, with a relatively small coefficient equal to 0.06 .

\section{Weak exogeneity and Granger causality tests}

In order to better understand the dynamic relationships among the four variables and refine the model, we carried out weak exogeneity tests of the null hypothesis that all adjustment parameters (i.e., rows of matrix $\alpha$ ) associated with a given variable $\mathrm{z}_{\mathrm{j}}$ were equal to zero. An exogenous variable, although it may enter the long-run equilibrium, is not itself caused by the other variables of the VAR (or VEC) model, and there is therefore no loss of information in not modelling its determinants (i.e., not including $\Delta \mathrm{z}_{\mathrm{jt}}$ as a lefthand-side variable of the model). Instead, the model can then more simply be conditioned on that variable by introducing it as a right-hand-side variable (in first difference $\Delta \mathrm{z}_{\mathrm{jt}}$ ). The results indicated that the prices of food and agricultural commodities should be treated as endogenous to the system at any reasonable level of significance, whereas the null of weak exogeneity of the price of energy and wages could not be rejected. This suggested that the dynamics of the four variables was driven primarily by the wage rate in food retail as well as the price of energy, and that hypothesis was analysed further through Granger causality tests. We found that the price of food was Granger caused by the three remaining variables of the model, hence giving support to our broad logical framework. Agricultural prices were themselves Granger caused by food and 
energy prices but not by the wage rate in food retail, which conforms to intuition. Turning to the two variables previously characterised as weakly exogenous, the wage rate in food retail and the price of energy were not found to be Granger caused by any of the variables in the model, which is consistent with the results of the weak exogeneity tests.

\section{Vector Error Correction Model}

Based on the two sets of tests, we specified a conditional VEC that included food and agricultural prices as endogenous variables, with energy prices and wages treated as exogenous variables that entered the shortrun model (contemporaneously and in lagged form) as well as the long-run model. Further, in search of a more parsimonious specification, F-tests of nullity of the two coefficients associated with each variable were carried out. This showed that, among the conditioning variables, only one-month lagged energy prices were significant in the VEC model, while both endogenous variables (agricultural and food prices) were also only significant in the short-run model with a lag of one month. Most monthly dummies were significant, although there were exceptions (e.g., February, May, June, and November). Altogether, the series of tests suggested that the short-run dynamics of the VEC model was captured by a very parsimonious specification including only energy prices and both endogenous variables with a single lag. However, estimation of that model revealed some serious problems of residual autocorrelation and heteroskedasticity, and highlighting trade-offs between parsimony and robustness of the model. Through trial and error, we identified a preferred specification that included two lags of the endogenous variables, all monthly dummies, and both conditioning variables with a single lag. The estimation results are presented in Table 1 for that model.

Table 1: Estimated VEC models

\begin{tabular}{|c|c|c|c|c|c|}
\hline & $\Delta \mathbf{P}_{\mathbf{f}}$ & $\Delta \mathrm{P}_{\mathrm{a}}$ & & $\Delta \mathbf{P}_{\mathrm{f}}$ & $\Delta \mathbf{P}_{\mathrm{a}}$ \\
\hline \multirow[t]{2}{*}{ Error Correction } & -0.165 & -0.285 & $\mathrm{SD}_{\text {Jan }}$ & 0.011 & -0.018 \\
\hline & & & & [ 4.17] & {$[-2.87]$} \\
\hline \multirow[t]{2}{*}{$\Delta \mathbf{P}_{\mathrm{e}}$} & - & - & $\mathrm{SD}_{\mathrm{Feb}}$ & 0.006 & 0.005 \\
\hline & & & & [ 1.81$]$ & {$[0.67]$} \\
\hline \multirow{2}{*}{$\Delta \mathbf{P}_{\mathrm{e}}(-\mathbf{- 1})$} & -0.032 & 0.016 & $\mathrm{SD}_{\mathrm{Mar}}$ & 0.002 & -0.039 \\
\hline & {$[-2.09]$} & {$[0.46]$} & & {$[0.50]$} & {$[-4.92]$} \\
\hline \multirow[t]{2}{*}{$\Delta \mathbf{P}_{\mathrm{e}}(-\mathbf{2})$} & - & - & $S D_{\text {Apr }}$ & 0.002 & -0.016 \\
\hline & & & & [ 0.61] & {$[-2.05]$} \\
\hline \multirow[t]{2}{*}{$\Delta \mathbf{P}_{\mathrm{w}}$} & - & - & $S^{\text {May }}$ & 0.005 & 0.011 \\
\hline & & & & [ 1.51$]$ & [ 1.44$]$ \\
\hline \multirow[t]{2}{*}{$\Delta \mathbf{P}_{\mathrm{w}}(-1)$} & -0.112 & 0.062 & $S_{\text {Jun }}$ & 0.001 & 0.003 \\
\hline & {$[-2.24]$} & [ 0.53] & & {$[0.46]$} & {$[0.46]$} \\
\hline \multirow[t]{2}{*}{$\Delta \mathbf{P}_{\mathrm{w}}(-2)$} & - & - & $S_{\text {Jul }}$ & 0.004 & 0.036 \\
\hline & & & & [ 1.52] & [5.23] \\
\hline \multirow[t]{2}{*}{$\Delta \mathbf{P}_{\mathrm{f}}(-\mathbf{- 1})$} & -0.146 & -0.153 & $\mathrm{SD}_{\text {Aug }}$ & -0.004 & 0.034 \\
\hline & {$[-2.05]$} & {$[-0.92]$} & & {$[-1.52]$} & {$[4.86]$} \\
\hline \multirow[t]{2}{*}{$\Delta \mathbf{P}_{\mathrm{f}}(-2)$} & 0.099 & 0.178 & $\mathrm{SD}_{\text {Sep }}$ & -0.001 & 0.017 \\
\hline & [ 1.35$]$ & [ 1.04$]$ & & {$[-0.35]$} & [ 2.31] \\
\hline \multirow[t]{2}{*}{$\Delta \mathbf{P}_{\mathrm{a}}(-\mathbf{1})$} & -0.042 & -0.274 & $\mathrm{SD}_{\text {oct }}$ & -0.007 & 0.011 \\
\hline & {$[-1.15]$} & {$[-3.17]$} & & {$[-2.41]$} & [ 1.68$]$ \\
\hline \multirow[t]{2}{*}{$\Delta \mathbf{P}_{\mathrm{a}}(-\mathbf{2})$} & 0.021 & -0.168 & $\mathrm{SD}_{\text {Nov }}$ & -0.002 & 0.011 \\
\hline & {$[0.59]$} & {$[-1.99]$} & & {$[-0.67]$} & [ 1.72$]$ \\
\hline \multirow[t]{2}{*}{ C } & 0.000 & -0.005 & $\mathbf{R}^{2}$ & 0.497 & 0.580 \\
\hline & {$[0.17]$} & {$[-1.09]$} & Adj. $R^{2}$ & 0.440 & 0.532 \\
\hline
\end{tabular}

We first note that the model, overall, has satisfactory explanatory power with a R-squared equal to one half for the food price equation, and 0.58 for the agricultural price equation. The speed of adjustment coefficients associated with the error correction (EC) terms have the expected negative sign that is required for the model to return to its long run equilibrium following a shock. Further, the coefficients are highly statistically significant in both equations, and their magnitudes indicate a rather speedy process of adjustment 
back to equilibrium: the half-lives of the transitory dynamics describing food prices and agricultural prices are 3.8 months and two months, respectively.

The short-run dynamics are more difficult to interpret but a clear pattern emerges regarding the seasonality of the first endogenous variable: as compared to their December level, food prices are higher from January to July, and lower from August to November, with a particularly noticeable monthly hike in January (more than 1\%). The seasonality of agricultural prices is less obvious, although there is evidence of relatively low prices in the first quarter of the year, and relatively high prices in July and August.

The short-run impact of the lagged endogenous variables are unclear as the coefficients associated with the one-month and two-month lags often have opposite signs and similar magnitudes. For instance, rather counter-intuitively the short-run effect of a ten percent increase in agricultural prices is to lower food prices by $0.4 \%$ the following month, but half of that increase then disappears in month two. Similarly, the two coefficients associated with lagged food prices in the agricultural price equation almost offset each other. Meanwhile, the coefficients of the weakly exogenous variables (wages in food retail and energy prices) are not very significant in the agricultural price equation, and have a negative sign that is difficult to interpret in the food price equation. Finally, we note that the constant is equal to zero (food price equation) or small and insignificant (agricultural price equation), which indicates the absence of linear structural change affecting producer technology and/or consumer preferences. All in all, the dynamics of food price formation is dominated by the relatively speedy adjustment to a long-run equilibrium as well as seasonal effects.

The statistical properties of the model are based on the assumption that the residuals in equation (2) are white noise, which was tested ex-post. By application of appropriate tests, we concluded that the estimated model was consistent with the underlying assumption of homoskedasticity and absence of autocorrelation, but violated the normality assumption. That last result, while not entirely satisfactory, is however rather commonly encountered in empirical applications of long time series.

Finally, Figure 2 presents the impulse response functions describing how food prices react to shocks affecting the three other variables of the model, hence providing a better understanding of how long-run model, short-run model, and volatility of time-series all contribute to the formation of food prices. Somewhat surprisingly in light of the relatively large adjustment coefficients reported previously, but in line with much of the literature on the subject, the figure indicates that food prices only stabilise after a significant period of time following a shock, with some adjustment still visible 24 months after the perturbation. Food prices respond the most to shocks affecting agricultural prices, which we explain by the importance of that variable in the long-run equilibrium (3) combined with its large variability evident in Figure 1. Next come energy prices, the relatively small influence of that variable on the long-run equilibrium being somewhat offset by its extreme volatility. The opposite explanation applies to the wage rate in food retail: although wages have a large influence on food prices in the long-run, as shown in equation (3), their limited variability implies that food prices respond little to a typical shock affecting that variable.

\section{Discussion and Conclusion}

This paper has used time-series econometrics to investigate the dynamics of food price formation in Finland. We have established the existence of a long-run equilibrium relationship between the prices of food and those of the main elements of the food marketing bill, namely agricultural commodities, energy and labour. Further, a simple vector auto-correction model shows that, after controlling for seasonal effects, those three variables alone explain about half of the variability in food prices since Finland joined the EU in 1995. Following a shock, convergence to the long-run equilibrium takes more than two years, although half of the adjustment typically occurs within 6-8 months (Figure 2).

In modern food-chains, large quantities of non-agricultural inputs are added to raw commodities in order to produce the final products that consumers ultimately purchase from retail stores. Our results indicate, however, that agricultural prices remain, quantitatively, the main determinant of food prices in Finland, with a long-run pass-through rate of nearly one third. Meanwhile, energy prices play a significant but quantitatively more limited role in determining the equilibrium level of food prices, although they are important in explaining food price variability. These findings are consistent with those reported for the US by Baek \& Koo (2010) as well as Lambert and Miljkovic (2010) ${ }^{2}$. Although they confirm the existence of

\footnotetext{
${ }^{2}$ To the best of our knowledge, the dynamics of food price inflation has not been analysed econometrically in any EU country, which gives novelty to our work but makes comparison difficult.
} 
strong linkages between agricultural and energy markets, they also suggest that the role of energy prices in driving food price inflation should not be exaggerated.

Further, the analysis indicates that other economy-wide factors, which tend not to attract much attention from policy-makers and the media, are also very important in determining food price inflation (if not volatility). Hence, it follows from the estimated co-integration relationship that wages in food retail have a strong influence on Finnish food prices. The finding that those wages are themselves weakly exogenous to the model suggests that their determination lies largely outside of the food chain and results from an equilibrium on the Finnish labour market.

The analysis presented above could be extended in many directions in order to increase the robustness of the results and improve our understanding of food price formation in Finland. At a methodological level, it is for instance possible that the price dynamics is fundamentally different in periods of price stability and periods of price instability, and it would therefore seem interesting to test for the presence of structural breaks and/or the existence of different regimes of food price formation ${ }^{3}$. At an empirical level, it seems also likely that, as shown by Leibtag (2009) for the US, the dynamics of food price formation varies substantially for the different sub-sectors and links of the food chain. Hence, further insights would be gained from disaggregation of the analysis across food industries (e.g., meat, dairy) and the explicit investigation of price formation at the wholesale level. Finally, a comparative study of price formation in the different countries of the EU or the Baltic region would help in deriving general conclusions regarding the efficiency with which Finnish food markets operate.

Figure 2: Impulse response functions

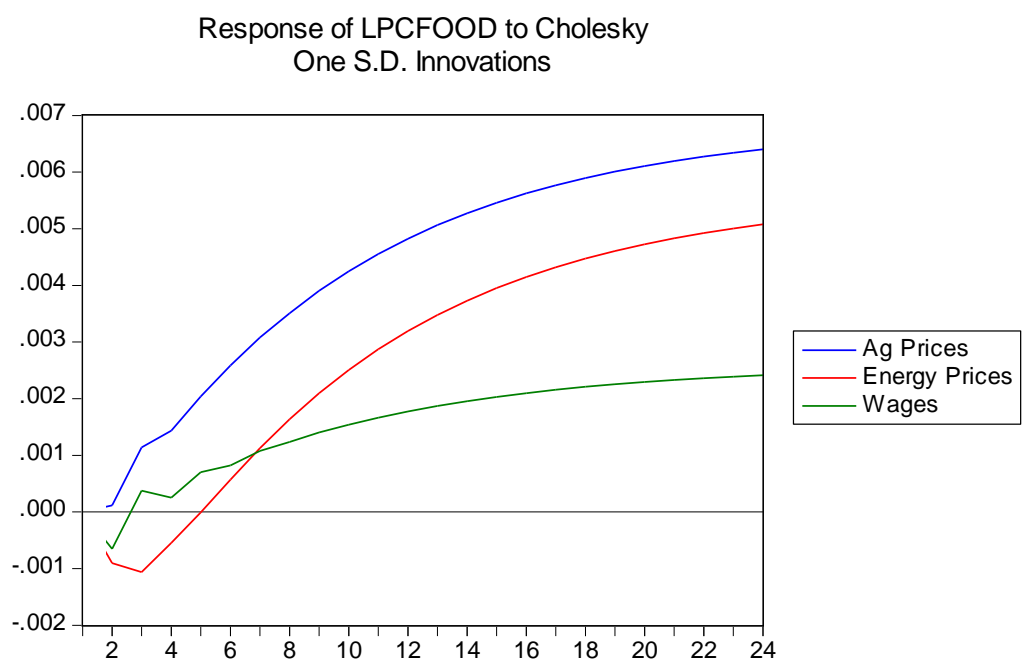

\section{References}

Baek, J., \& Koo, W. W. (2010). Analyzing factors affecting U.S. food price inflation, Canadian Journal of Agricultural Economics, 58: 303-320.

Doornik, J. A. (1995). Testing General Restrictions on the Cointegrating Space, manuscript.

Harris, R., \& Sollis, R. (2003). Applied time series modelling and forecasting, John Wiley \& Sons, Chichester, UK.

Johansen, S. (1995). Likelihood-based inference in cointegrated vector autoregressive models, Oxford University Press, Oxford, UK.

Lambert, D. K., \& Miljkovic, D. (2010). The sources of variability in U.S. food prices, Journal of Policy Modeling 32: 210-222.

Leibtag, E. (2009). How much and how quick? Pass through of commodity and input cost changes to retail food prices, American Journal of Agricultural Economics, 91(5): 1462-1467.

\footnotetext{
${ }^{3}$ However, the limited size of the dataset makes this inquiry difficult.
} 